\title{
Serbest Zaman Etkinliği Olarak Dijital Oyunlar ve Toplumsal Cinsiyet
}

\author{
DOI: $10.26466 /$ opus.748560
}

\author{
* \\ Ümmü Arda*- Rabia Kaya**- Veli Ozan Çakır*** \\ * Dr. Öğr., İstanbul Üniversitesi, Cerrahpaşa, Lisansüstü Eğt. Ens., İstanbul/ Türkiye \\ E-Posta: ummu.rda@gmail.com \\ ORCID: $\underline{0000-0002-9853-5163}$ \\ ** Arş.Gör.,Nişantaşı Üniversitesi, Beden Eğitimi ve Spor Yüksekokulu, İstanbul/Türkiye \\ E-Posta: $\underline{\text { rabia.kaya@nisantasi.edu.tr ORCID: 0000-0002-1382-1065 }}$ \\ *** Doç. Dr., Alanya Alaaddin Keykubat Üniversitesi, Spor Bilimleri Fakültesi, Antalya/Türkiye \\ E-Posta: ozan.cakir@alanya.edu.tr \\ ORCID: 0000-0001-7996-2138
}

Öz

1970'lerden bu yana, video oyunlar giderek daha popüler hale gelmiştir. Ayrıca günümüzde hem kadinlar hem de erkekler tarafindan tercih edilen bir serbest zaman aktivitesi durumundadır. 'Toplumsal cinsiyet', kadın ve erkek olmanın toplumsal kategorilerine atfedilen kültürel anlamları ifade etmekte ve ayrica kadin ve erkeklerin tercihlerini de etkilemektedir. Bir serbest zaman aktivitesi olarak dijital oyunlar hem kadın ve erkeklerin hem de farklı yaş gruplarmın tercihleri arasındadır. Çocukluk dönemi oyuncaklarında görünür hale gelen oyuncak tercihleri, ergenlik ve yetişkinlik döneminde oynanan dijital oyunlarda da görülmektedir. Kadın ve erkekler arasında dijital oyun tercihleri bakımından farklılıklar bulunmaktadır. Yapılan araştırmaların sonuçları erkeklerin kadınlardan daha fazla şiddet içeren oyun oynamayı tercih ettiğini göstermektedir. Erkek oyuncular strateji, aksiyon ve dövüş türlerine katılmayı tercih ederken, kadın oyuncular bulmaca, sosyal, müzik ve dans, eğitim türleri oynama eğilimindedir. Buna ek olarak, erkekler ve kadınlar arasında günlük ortalama dijital oyunlara katılma süreleri bakımından da farklılaşma vardır. Bu çalışmanın amacl, konu ile ilgili yapılan araştırmaları inceleyerek toplumsal cinsiyet ve dijital oyunlar arasındaki ilişkiyi ortaya koymaktır. Araştırma, derleme bir çalışma olup cinsiyet ve dijital oyunlar hakkındaki araştırma literatürünü gözden geçirmektedir.

Anahtar Kelime-

ESpor, Dijital Oyun, Serbest Zaman, Toplumsal Cinsiyet, Okul Öncesi Çoler: cukluk 


\title{
Digital Games as a Leisure Time Activity and Gender
}

\begin{abstract}
Since 1970's digital games have become progressively popular. It is also a leisure time activity that preferred by both men and women today. The term of 'gender' is usually used to refer to the cultural meanings male and female social categories in societies and also it affects men's and women's preferences. As a leisure time activity, digital games are among the preferences of both men and women and different age groups. Toy preferences that become visible in childhood toys are also seen in digital games during adolescence and adulthood. There are differentiations between men and women in terms of digital game preferences. The results of the researches show that men extremely played more violent video games than women. While male gamers prefer to participate the strategy, action and fighting genres, female gamers tend to play puzzle, social, music and dance, educational genres. In addition, there is a difference between men and women interms of their time to participate in average daily digital games. The aim of this study is to investigate the relationships between digital games and gender by examining the research on the subject. This study reviews the research literature on gender and dijital games.
\end{abstract}

Keywords: ESports, Digital Games, Leisure Time, Gender, Pre-school Childhood. 


\section{Giriş}

Yetenek ve zekâ geliştirici yönüyle belli kurallara dayanan, iyi vakit geçirmeye yarayan eğlence olarak tanımlanan oyun (Türk Dil Kurumu, 2020), geçmişten günümüze kendi dönemlerindeki anlamları ile var olup aynı zamanda bir sonraki dönemlere de kültür aktarımı rolü üstlenmiştir.Kimi oyunlar dinsel (Onur, 1992, s18; 29-30) bir amaç ile oynanrrken kimi oyunlar medeniyetlerin mevcut coğrafi özellikleri ile şekillenmiştir.Öte yandan oyunun eski zamanlardan itibaren cinsiyet ile ilişkisi de çoğu zaman oyunların şekli ya da amacı doğrultusunda farklılık göstermiştir.Modernleşmeye doğru gidildiğinde ise oyunun daha çok yaygınlaştığı ve dönüşüm gerçekleştirdiği görülmektedir. Bu durum kitlelerin serbest zaman etkinliklerine de yansımaktadır. Oyun, gerek kitle sporu kapsamında keyif veren ve eğlendiren bir araç anlamında fiziksel aktivite gerek ise zihinsel oyunlar ya da strateji oyunları şeklinde seyrini sürdürmüştür.

Doğa tarafından verilen hayvanları ve insanları kapsayan oyunların (Huizinga, 2006, s.17) ilkel yaşamdan modern yaşama geçilirken ya da modernitenin devamında yaşadığı değişim, tıpkı eski zamanlarda olduğu gibi yine hem kültürü hem de cinsiyetlere atfedilen şeklini sürdürmeye devam etmektedir. Keyif veren ve eğlendiren oyunlara artan talep, teknoloji ve ekonominin de bu ilgi karşısında harekete geçmesini sağlamıştır (Kemiksiz, 2019, s.60). Oyunlara karşı artan ilgi, 1980'lerde Pacman furyası ile kitleleri başka bir hazza sürükleyerek kitlelerin zihinlerindeki klasik oyun algısına "dijital oyun" kavramını da ekleyerek etkisini günbegün artırmaya devam etmektedir.

Öte yandan büyük spor kulüpleri de bu artan ve yaygınlaşan ilgiye kayıtsız kalmayarak dijital oyunlar için yatırım yapmaktadır (Akgöl, 2019, s.212). Dijital oyunlar, günümüz dünyasında eSpor kapsamında mega organizasyonlar şekliyle de varlığını sürdürmekte hatta hemen hemen çoğu ülkenin eSpor ile ilgili bir federasyonu bulunmaktadır. Ancak görünen şudur ki tüm bu gelişmelerin yanında klasik oyun ve oyuncaklardaki (Blakemore ve Centers, 2005, s.619) gibi dijital oyunda da cinsiyetlerin tercih ettiği oyunlar farklılık göstermektedir (Can, 2003, s. 35).

Modern zamanda her yaştan kişinin yoğun çalışma hayatı dışında serbest zamanlarında faydalanabileceği bir rekreatif aktivite olarak kabul 
edilen dijital oyunlar, doğru kullanıldığında etkin bir spor aracı olarak düşünülmektedir (Esentaş, Güzel ve Vural, 2018, s.73). Çalışmamızda farklı yaş ve cinsiyetten kişilerin tercih ettiği oyunlardaki farklılığın neden olduğu durumlar öncelikle araştırmacıların gözlemi ile başlayan süreçten sonra mevcut literatürün taranması ve ulaşılan kaynakların doküman incelemesi ile tartışılmaktadır. Bu doğrultuda çalışmamızda alanyazında var olan cinsiyet-dijital oyun ilişkisi ile bu farklılığın geçmişten günümüze değişip değişmediği ya da gelişip gelişmediği irdelenmektedir.

Çalışmamızın metodolojisini oluşturan nitel araştırma yöntemlerinden olan doküman incelemesi; araştırma konusunun hedeflediği olgu ya da olguları içeren yazılı materyallerin analiz edilmesinde kullanılmaktadır. Bu yöntem tek başına bir araştırma için yeterli olabileceği gibi diğer veri toplama yöntemleri ile birlikte de kullanılabilmektedir (Yıldırım ve Şimşek, 2016, s. 189). Doküman incelemesi ile birlikte yapılan literatür taraması ise; araştırma konusu ile ilgili daha önce yayınlanan eserlerin araştırılması, bulunması, incelenmesi, okunması, tasnif edilmesi, özetlenmesi ve sentez edilmesi gibi çalışmaları içermekte ve bu çalışmaların analizinin hedefi ise literatürde araştırılan konunun bulunduğu konumu tespit etmek, literatürdeki boşluk ve es geçilenleri ortaya tıpkı bir puzzle gibi birleştirerek koymaktır ve yapılan çalışmanın da önceki literatür içerisinde nereye konumlandırılacağını tespit etme olarak ifade edilmektedir (Demirci, 2014, s.73). Literatürde bu alan ile ilgili sınırlı sayıda araştırma olması sebebiyle de amacımız konu ile ilgili alanyazına katkıda bulunmaktır.

\section{Oyun}

İnsanlık tarihinin başlangıcından 5794uy ana, insanoğlunun en temel etkinliklerinden biri olan oyun, kültürün oluşumundan daha eskilere dayanmaktadır. Eyleme mana katan bağımsız bir unsuru barındıran oyunda hayatın doğrudan gereksinimlerini aşan bir unsur bulunmaktadır. Huizinga (2006), bu unsurun 'oynamak' olduğu görüşündedir (Huizinga, 2006, s.17). Huizinga, oyunun doğa tarafından verildiğini vurgulayarak, herkesin gözleyebileceği, hem hayvanları hem de insanları kapsayan bir etkinlik olduğunu ileri sürmektedir (Huizinga, 2006, s.19). 
Her şeyden önce denilebilir ki oyun, isteğe ve arzulara bağlı olarak gerçekleştirilen gönüllü bir faaliyettir. Zoraki oyuna oyun denilemez. Bu açıdan düşünüldüğünde oyun, serbest zamanlarda yapılmaktadır. Oyun günlük yaşam içerisinde bir mola verme ve gündelik yaşamın bir süsüne benzemektedir (And, 2012, s.28). D. Parlett, oyunları, bitiş noktası ve anlamlılığı olan faaliyetler olarak ele alır. Ona göre oyun, hedefi olan ve yarışma sonucunda hedefe ulaşılan etkinliktir. Oyun içinde kural ve hedeflere yönelik hazırlanan nesneler ve oyunun bir kazananı bulunmaktadır (Parlett, 1992 akt.Salen and Zimmerman, 2004). Abt (1987) oyunların, her yaş ve her durumdan öğrenciler için birçok konunun kavram ve gerçeklerini verimli bir biçimde ilettikleri için etkili bir motivasyon ve eğitim aracı olduğu düşüncesindedir (Abt, 1987, s.13).

Caillois, oyunu kurallı, inandırıcılığı ve kendine özgü zaman-mekanı olan, sonuçları önceden bilinmeyen, gönüllülük temelinde ortaya konulan bir eylem olarak ele almaktadır (Caillois, 1961, s.9-10). Oyunun ne olduğu ile ilgili birçok tanım yapılmış olmasına rağmen ortak nokta, oyunun özellikle çocuklar için çok önemli bir uğraşı olduğudur (Akgül ve Öztürk, 2004, s.54).

Oyunun geçmişi insanlık tarihinin geçmişi kadar eskiye dayanır. Tarihin her döneminde çocuklar, oyun ve oyuncaklarını kendileri üretmişler veya büyüklerinden gördükleri oyunları kendilerinde düzenleyerek oynamışlardır (Güneş, Tuğrul, Ertürk ve Altınkaynak, 2014, s.2). Eski tarihlere dayansa da oyun ile ilgili, paleolitik ve neolitik dönemler üzerine bulgular çok azdır. İlkel dönem toplumlarında popüler oyunlar, spor ile birleştirilmiş savaş oyunlarıdır. Savaşa hazırlık amacı güden bu oyunlar, savaş kabiliyetinin halk tarafından görülmesi bakımından büyük önem taşımaktadır. Antik Mısır kültüründe ise Senet, en popüler oyunlardan bir tanesiydi. Oyun tahtasının üç sırada otuz kareye bölünmesi ile oynanan bu oyunun dini açıdan önemi bulunmaktaydı. Mısırlılar bu oyun ile başka dünyaya geçtiğine inanırlardı (Şentuna, 2013, s.119).

Eski Yunan'da da dini gelenekler ile oyuncak arasında ilişki görülmektedir. Örneğin kız çocuklarının oyuncak bebeklerini Yunan Tanrıçası Artemis'e; erkek çocuklarının ise çember ve topaçlarını Zeus ve Maia'nın oğlu Hermes'e hediye etme adetleri bulunmaktadır. Oyuncakların, ait oldukları dönemlerin toplumsal, kültürel ve ekonomik 
koşullarını da yansıttığı görülmektedir. En eski oyuncakların yapımında kullanılan materyaller, taş, kemik, kuru meyve, mum, kil, tahta ve benzerleriyken sonradan bu materyallere kumaş da eklenmiştir. Dünya Ortaçağı yaşarken ise dövme demir oyuncak yapımında kullanılmaya başlanmıştır. Sanayileşmenin ortaya çıkardığı modern oyuncak ise geleneksel hayat tarzının ürünü olan oyuncaktan çok farklıdır. Geleneksel yaşam kültürünün ürünü, oyuncaktan çok oyun nesnesi konumunda iken modern oyuncak oyundan bağımsız olarak varlığını sürdürmeye devam etmektedir. Modern oyuncak oyun dünyasına hazır olarak sunulmuştur ve bireysellik içermektedir (Onur, 1992, ss..18; 29-30). Gönüllülük esasına dayanan oyun, günümüze yaklaştıkca sokaklardan iç mekanlara doğru taşınmıştır (Pala ve Erdem, 2011, s.54). Günümüzde bilişim teknolojilerindeki yaygınlaşma, dijital oyunların ortaya çıkmasına yardımcı olmuştur. 60'lı yıllardan günümüze hızla gelişen dijital oyunlar, kitleleri peşinden sürükleyen bir endüstriye dönüşmüştür. Gelişen teknoloji oyun ve oyuncak kavramlarına yeni boyutlar kazandırmıştır. Bu kavramlar, artık bilgisayar oyunları, video oyunları ve mobil oyunlar olarak karşımıza çıkmaya başlamıştır (Kirriemuir, 2002). Dijital oyunlar, eğlence biçiminin son derece popüler bir hali olarak görülmektedir (Crawford, 2005, s.259).

Dijital oyunların artan popülaritesi, platform ve oyun türlerinin çeşitlenmesine neden olmuştur. Oyunun sosyal bağlamları değişmiş, dijital oyunlar kitle eğlence teknolojisine dönüşmüştür (Bryce and Rutter, 2003, s.5). Oyunun, artık farklı ortamlarda farklı gidişatları içerecek biçimdeki değişimi kendi içinde önce kişisel sonra etkileşimde bulunma imkanı veren teknolojik gelişimlerle kitlesel bir nitelik kazanmıştır. Bu sebeple oyuna ilişkin rekabet unsuru da kitlesel bir boyutta tekrardan yorumlanmaktadır. Böyle bir yorumlamanın somut örneği olarak elektronik sporlar (eSpor) öne çıkmaktadır. Ortaya çıkması ile beraber ciddi bir gelişim göstermeye devam eden ve yönetilen bir etkinlik alanı olarak dijital oyun organizasyon ve turnuvaları, resmi bir spor branşına evrilmekte, profesyonellik kazanmaktadır. Ancak bu noktada akılda tutulması gereken, oyunun, zorunlu bir etkinlik olarak algılandığ 1 noktada gönüllülük ve hür yaratıcllığa olanak sağlayan etkinlik olma özelliğinden uzaklaşmasıdır. Örneğin futbol dünyada bir endüstri ve ciddi bir iş alanıdır ancak sokaklarda, parklarda hala tecrübe edilen bir 
oyun anlamını taşımaktadır. Dijital oyunlar da benzer bir biçimde kişilerin serbest zaman süreleri içerisinde gönüllülük içinde katılabileceği bir oyun nesnesi olarak kalmaya devam etmektedir (Ercansungur ve Canbaz, 2019 s.2011). Dijital oyunlarda yaşanan gelişim, bu alana yapılan yatırımları artırmış bilinen spor kulüpleri eSpor takımları kurmaya başlamış ve bu girişimlerle marka değerlerine katkı sağlamışlardır. Ayrıca dünyaca ünlü sporcular da eSpor alanına yatırım yapmaya başlamıştır. Eski NBA oyuncusu Rick Fox, Saquille O'Nea, NBA kariyerine hala devam eden Jonas Jerebko, beyzbol oyuncuları Alex Rodriguez ve Jimmy Rollins örnek olarak verilebilir (Akgöl, 2019, s.212).

\section{Espor Kavramı ve Gelişimi}

Dijital Dünyada Rekabet, eSpor ve Topluluk Yönetimi Çalıştayı Sonuç Raporuna (2017) göre elektronik spor, teknolojinin hızla geliştiği günümüzde sporun yeni bir yüzü olarak bilinen bilgisayar, telefon, konsol vb. aracılığ 1 ile el-göz koordinasyonu sağlanarak oynanan dijital oyunların genel bir adıdır. Espor, çevrimiçi ya da çevrimdışı bireysel ya da grup şeklinde oynanabildiği gibi kendi içerisinde çeşitleri olan bir çatıdır.

70 ve 80 'li yıl gençliğinin bir araya gelip, oyun oynadığı ve bu sırada ortak bir kültürü paylaştıkları eğlence yerleri olarak isimlendirilen atari salonlarında elektronik spor kavramının gelişmeye başladığı söylenebilir. Bu dönemin hakimiyeti ise 10-15 yıl kadar devam etmiştir (Akın, 2008, s.18). Bilgisayarların ortaya çıkmasından yaklaşık $10-20$ yıl önce popüler olan masa oyunları, bilgisayarlar ile birlikte başka boyutlar kazanmıştır.Oyunlar, insanların bilgisayarları evlerine taşımasının önemli nedenlerinden biri haline gelmiştir.Televizyonlara takılabilen bilgisayarlara göre daha ucuz fiyatta olan harici oyun konsolları yoluyla insanlar, elektronik oyunlarla tanışma fırsatı bulmuştur.Bu da elektronik oyunların daha geniş kitlelere yayılmasını sağlamıştır.Ev tabanlı ilk oyun Pong, 1972 yılında satılmaya başlanmıştır.Ev tabanlı konsol oyunları ve jetonlu oyun makineleri ile büyük kitleler yakalanmıştır.Pac-Man gibi dünyaca ünlü oyunlar, 1970 ve 1980 'lerin gençliğini peşinden sürüklemiştir.Konsol sistemleri ile eğlence artık oyuncuların kendi odalarına girmeyi başarmıştır.1985 yılında Nintendo tarafından piyasaya sürülen Super Mario Bros. kendinden sonraki oyunlara örnek teşkil etmiştir. Doom, 
Quake ve Tomb Raider gibi oyunlar ise, oyuncuyu başka bir gerçekliğin içinde gibi hissettiren görüntüleri ile oyuncuları büyülemiştir. Grafikler ise, hız ve performansın da artması ile git gide zenginleşmiştir. Böylelikle Play Station, Xbox gibi yeni oyun konsolları da piyasada popülerlik kazanmıştır (Fox, 2002, s.1-2).

Öte yandan Hagenuk MT-2000 model telefon 1994 yılında piyasaya sürülmüş ve bu model, oyun oynanabilen ilk telefon olmuştur.Bu telefon, kullanıcılarının basit bir biçimde Tetris oyunu oynayabilecekleri biçimde tasarlanmıştır (Nick, 2014).1997 senesinde Nokia, 6110 model telefonu ile kullanıcılarına Snake oyunu deneyimi sunmuştur.Ilk dönem cep telefonlarının ekran özellikleri ve grafik işlemcilerinin kapasitesinin düşüklüğü gibi nedenlerden dolayı mobil oyunlar, kullanıcılar tarafından olağanüstü bir ilgi ile karşılanmamıştır. Fakat gelişen teknoloji ile cep telefonlarının ekranları genişleyerek dokunmatik hale gelmiştir. İnternete bağlanabilme olanağı, veri hızının artışı, yüksek özellikli grafik ve bellek kullanımı vb. nitelikleri ile cep telefonları oyun oynama etkinliğini kullanıcılar için cazip hale getirmiştir (Altuntaş ve Karaarslan, 2017, s.281). En genel hali ile eSporun tarihsel gelişim dönemleri Tablo.1'de gösterilmiştir.

Tablo 1.eSporun Tarihsel Gelişimi

\begin{tabular}{|c|c|c|c|}
\hline & Dönemin Özelliği & Oyun Türü & Dönemin Önemli Olayı \\
\hline 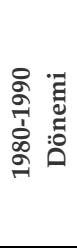 & $\begin{array}{l}\text { Arkadaş arasında } \\
\text { başlayan ve amacın en } \\
\text { yüksek skoru geçmeye } \\
\text { çalışmak olduğu bu dö- } \\
\text { nemde organize turnu- } \\
\text { valar yapılmaya } \\
\text { başlanmıştır. }\end{array}$ & $\begin{array}{l}\text { Arcade oyun } \\
\text { makinaları }\end{array}$ & $\begin{array}{l}\text { Atari, } 1980 \text { yılında ilk video oyun } \\
\text { turnuvası olan "Space Invader- } \\
\text { sTurnuvası"nı düzenlemiştir. } \\
\text { Turnuvaların artış göstermesi ile büyük } \\
\text { firmaların espor oyuncularına sponsor } \\
\text { olma dönemi başlamıştır. }\end{array}$ \\
\hline 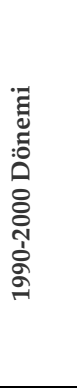 & $\begin{array}{l}\text { Arkadaşlar arasında } \\
\text { oynama anlayışı PC } \\
\text { oyunculuğunun da } \\
\text { yükselişi ile yerini reka- } \\
\text { betin üst düzey } \\
\text { yaşandığı gerçek espor } \\
\text { mücadelelerine } \\
\text { bırakmıştır. }\end{array}$ & $\begin{array}{l}\text { Dönemin } \\
\text { başlarında } \\
\text { FSP(First Player } \\
\text { Shooter) arcade } \\
\text { oyunlar tercih } \\
\text { edilse de 90'ların } \\
\text { sonuna doğru } \\
\text { Starcraft gibi } \\
\text { strateji oyunları } \\
\text { da döneme dahil } \\
\text { olmuştur. }\end{array}$ & $\begin{array}{l}1997 \text { yılındaki “Quake” turnuvası, ilk } \\
\text { gerçekespor etkinliği olarak kabul edilir } \\
\text { ve } 2 \text { bin katılımcıyı çeken bu turnuvanın } \\
\text { ödülü ise, Ferrari olarak belirlenmiştir. } \\
\text { Cyberathlete Profesyonel Ligi (CPL) ku- } \\
\text { rulmuş veCPL'nin ilk turnuvası } \\
\text { yapılmıştır. }\end{array}$ \\
\hline
\end{tabular}




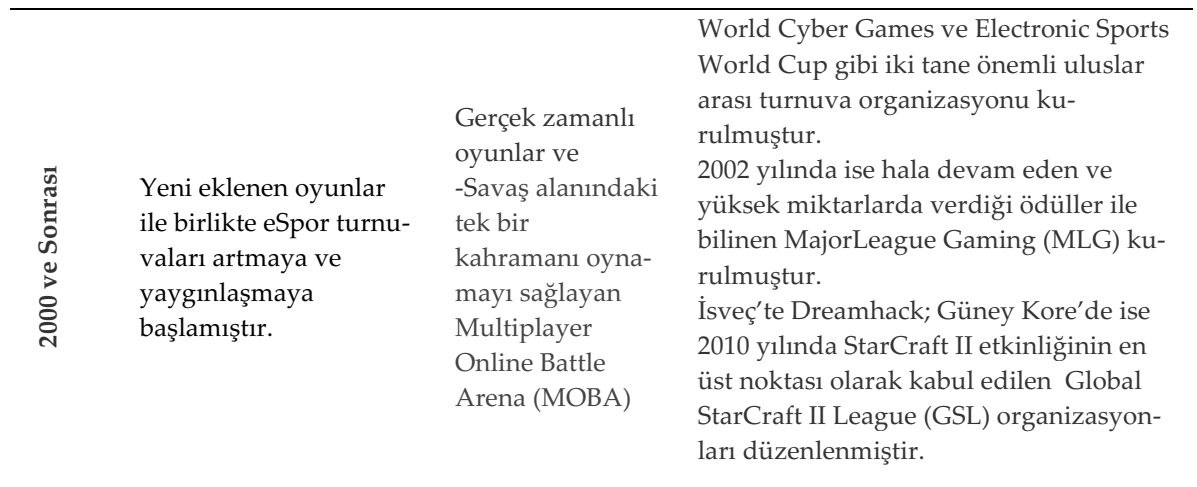

Kaynak: Dijitalsporlar: 'Dünyada eSpor' 29 Nisan 2015 (Çevirmiçi) https://dijitalsporlar.com/makaleler/dunyada-espor (Erişim Tarihi: 4 Nisan 2020).

Oyunlarla ilgili tek gelişim sadece türlerde değil aynı zamanda bu gelişim işlem gücü ve yapay zekada da önemli bir gündem haline gelmiştir. Örneğin 1997 yılında Dünya satranç şampiyonu Gary Kasparov'u IBM'nin Deep Blue bilgisayarı mat etmeyi başarmıştır (Yılmaz ve Çağıltay, 2004, s. 2). E-sporun teknoloji ile olan sıkı ilişkisi ve ilerleyişini aynı hızla gerçekleştirmelerinin bir sonucu olarak sözü geçen alan, kendi sektörünü oluşturmaya başlamıştır. Birbirinden bağımsız değerlendirilemeyen bu iki kavram etkileşimleri doğrultusunda eSpor oyuncularının başarısını artırmak adına en gelişmiş ekran kartları ve yeni nesil işlemcilere sahip oyun bilgisayarları, oyunlara özel klavye, mouse, kulaklık gibi donanımsal ve yardımcı ekipmanlar ile oyunculara teknolojiyi yaşatmaktadır (Kemiksiz, 2019, s.60).

Tablo.1 incelendiğinde elektronik oyunlar konusundaki en önemli gelişmenin online oynanan oyunlarda gerçekleştiği görülmektedir. On binlerce oyuncunun aynı anda buluştuğu sanal ortamlar bazen yönetilen karakterin gelişimi için rekabet ve mücadeleye sahne olurken bazen de güvenlik güçlerinin oluşturduğu grupların sonu gelmeyen dövüşlerine ev sahipliği yapmaktadır (Yılmaz ve Çağıltay, 2004, s.2). Günümüzde telefonların çevrimiçi mağazalarından istenilen oyun seçilip indirilerek telefonda veya tablet cihazlarda oynanabilmektedir.

Tüik 6-15 Yaş Grubu Çocuklarda Bilişim Teknolojileri Kullanımı ve Medya (2013) verilerine göre 6-15 yaş arası çocukların cep telefonu kullanımına başlama yaşı 10'dur. Cep telefonu kullanım amaçları ise ilk 
sirada \%92,8 oranla konuşma bulunmakta, bunu $\% 66,8$ oran ile oyun oynamak takip etmektedir. 6-10 yaş arası cep telefonu kullanan çocukların $\% 80$ 'i ile 11-15 yaş arasındaki çocukların \%62,9'u cep telefonlarından oyun oynadıklarını göstermektedir (Türkiye İstatistik Kurumu, 2013).

Tüik Hane halkı Bilişim Teknolojileri Kullanım Araştırması (2019) verilerine göre Türkiye'de internet kullanımı 16 ve 74 yaş arası bireylerde 2018 yılında \%72,9 iken 2019 yılında \%75,3'e erişmiştir (Tüik, 2019).

We Are Social Digital 2020 raporuna göre Türkiye'de 16-64 yaş arasi, internet erişimi için mobil cihazları kullanan kişilerin günde internette geçirdikleri ortalama süre 4 saat olarak dünya ortalaması üzerindedir. Aynı rapor, Türkiye'de 16-64 yaş arası internet kullanıcılarının günde ortalama 58 dakikasını oyun konsolu kullanarak geçirdiğini göstermektedir (We Are Social Digital, 2020).

\section{Cinsiyet, Oyun ve Oyuncaklar}

Cinsiyet (sex) ise, kadın ve erkeğin biyolojik farklılığına işaret etmektedir. Biyolojik farklılıklar her toplumda o toplumun bakışı ile kültürel olarak yorumlanıp değerlendirilir. Böylelik ile hangi cinsiyetin nasıl davranacağına, gücü nasıl elinde bulunduracağına, küçüklüğünden yetişkinliğine kadar davranış kalıbının ne olacağı ile ilgili toplumsal beklentiler geliştirilirken bir yandan da toplum içerisinde toplumsal cinsiyet kaynaklı farklilıklar ve eşitsizlikler ortaya çıkmaktadır (Ecevit, 2003, s.83). Toplumsal cinsiyet (gender), ideoloji tarafından erkek ve kadının biyolojik farklılaşmasına yüklenen anlam ve değerler iken aynı zamanda kurumların sosyal çevre ile karşılıklı, iç içe geçmiş, karışık ilişkilerinin ortaya çıkardığı bir ürün olan, kültürel bir olgudur (Baloğlu ve Davutoğlu, 2009, s.74).

Öte yandan toplumsal bir kurum olan aile de rol paylaşımının ve toplumsal cinsiyete dayalı eşitsizliklerin yeniden üretildiği bir kurum olarak bilinmektedir (Güder ve Yıldız, 2016, s.440). Çocukların tercih ettiği oyunların cinsiyetlerine göre farklılık göstermesinin de toplumsal cinsiyet kavramı ile ilgili olduğu; oyun, oyun arkadaşı ve oyuncak tercihleri ile de cinsiyet rolü gelişimleri arasında güçlü bir bağ olduğu (Güder ve Alabay, 2016, s. 92) ve aynı zamanda onların toplumsal cinsiyet algılarının oluşmasında aile faktörünün oldukça önemli olduğu bilinmektedir (Güder ve Y1ldiz, 2016, s.440). 
Cinsiyet farketmeksizin çocukların hayatları için önemli rolleri olan oyuncaklar, bilişsel becerilerini geliştirdiği gibi diğer çocuklarla sosyal etkileşim kurmasını da sağlamaktadır. Ancak oyuncaklar da büyük ölçüde cinsiyetli durumdadır. Erkek ve kız çocuklarının oyuncakları cinsiyetlerine göre farklılık göstermektedir (Blakemore and Centers, 2005, s.619). Rheingold ve Cook (1975) bundan 45 yıl önce 1-6 yaş arası kız ve erkek çocuklarının odalarını gözlemledikleri araştırmalarında erkeklerin kızlara oranla daha çok taşıt (araba, tır, vagon vb.), hayvan, makine, askeri oyuncaklar ve spor materyallerine sahip olduklarını ve odalarının hayvan motifleri vb. ile dekore edildiğini ileri sürmüşlerdir. Erkek çocuklarının odalarındaki oyuncak bebekler, kovboy, Kızılderililer ve oyuncak askerlerden oluşmaktadır. Kız çocukların odalarında ise daha fazla oyuncak bebek, daha fazla kadın figürü görülmüştür. Odalarında bebek ve ev bakımı ile ilgili daha fazla nesneye rastlanmıştır. Kız çocuk odalarının dekorasyonlarında çiçek desenleri, dantel, saçak ve fırfırların öne çıktığı gözlenmiştir (Rheingold and Cook, 1975, s.462).

Aynı araştırmada erkek çocuklarına kız çocuklarına sunulduğundan daha fazla çeşitlilik sağlandığı görülmüştür. Erkek çocuklarına makineler, askeri oyuncaklar, eğitim-sanat malzemeleri, uzaysal-zamansal nesneler, spor malzemeleri, oyuncak hayvan ve taşıtlar sunulmuş iken, kız çocuklarına bebekler, bebek evleri, ev ve mutfak malzemeleri sunulmuştur (Rheingold and Cook, 1975, s.462).

Çiftçi ve Özgün (2010) yaptıkları araştırmada resim çizme, evcilik oyunu, bebekler ile oynama, oyuncak makyaj aletleri ile oynama vb. etkinliklerin daha çok kız çocukları tarafından tercih edildiğini, erkek çocuklarının ise güreşme, hırsız polis oyunları, arabacılık, tamircilik oynama, blok ve puzzle yapma gibi etkinliklere katılma eğiliminde olduklarını ortaya koymuşlardır (Çiftçi ve Özgün, 2011, s.2257-2258). Pilten ve Pilten (2013) çalışmalarında, kız çocuklarının evcilik oyununu, mutfak oyuncakları ve bebekler ile oynadıklarını, erkeklerin ise daha çok çeşitli taşıt oyuncakları, puzzle, silah ve top vb. oyuncakları oyunlarında kullandıklarını tespit etmişlerdir. Ayrıca Rheingold ve Cook (1975) da bir önceki çalışmaya paralellik gösterir biçimde erkek çocuklarının oyuncaklarında daha fazla çeşitliliğin hakim olduğunu ileri sürmüşlerdir (Pilten ve Pilten, 2013, s.26; Rheingold and Cook, 1975, s.462). Güven (2018) 2.,3.,4.,5.,6.,7. ve 8. sınıf öğrencileri ile yaptığı araştırmada 8. sınıf öğrencileri hariç, 
arabanın erkekler; oyuncak bebeklerin ise kızlar tarafından tercih edildiğini ortaya koymaktadır (Güven, 2018, s.811).

Ayrıca Sezici ve Yiğit (2019), okul öncesi çocuklar üzerine yaptıkları araştırmada erkek çocuklarının itişli kakışlı oyunları kızlara göre daha fazla tercih ettikleri sonucuna ulaşmışlardır. Araştırmaya göre erkek çocukları kızlara oranla daha fazla şiddet içeren oyunları tercih etmektedir (Sezici ve Yiğit, 2019, s.184).

Letranchant ve arkadaşları (2016) ise kız çocuklarının daha çok mutfak setleri ve oyuncak bebekler ile zaman geçirirken erkek çocuklarının uçak ve araba gibi taşıt oyuncaklarına yönelmekte olduğunu, WalMart ve Toys R Us gibi büyük şirketlerin cinsiyete özgü oyuncakları pazarlama stratejilerini azaltmayı kabul etmiş olsalar da bu durumun şirketlerin genel olarak yaşadığı bir zorluk olduğunu ileri sürmektedir. Oyuncakların pazarlanmasında kullanılan reklamlarda oyuncak bebek ve pembe renkli oyuncakların tanıtımında kız çocuklarının, araba ve mavi renkli oyuncakların tanıtımında ise erkek çocuklarının seçildiği düşünülmektedir. Bu reklamlar ise televizyon ve çeşitli medya araçları yolu ile yayılarak klişeleşmenin ilk adımı atılmaktadır. Kuzey ülkelerinde yapılan çalışmaların sonuçları, erkek çocuklarına hitap ettiği düşünülen reklamlarda silahlar \%92, taşıtlar $\% 78$, bilim ile ilgili oyuncaklar \%77 oranında sunulmaktadır. Bu oranlar kız çocukları için müzik ile ilgili oyuncaklar için \%60 ve sanatsal oyuncaklar için \%73'tür (Letranchant, Laure, Maureau, Trioux and Hota., 2016, s.2).

Alabay ve Güder (2014) 2014 yılının en çok seyredilen 49 oyuncak reklamını toplumsal cinsiyet bağlamında inceledikleri çalışmalarında, ele aldıkları oyuncak reklamlarının \%77,6'sının cinsiyetçi niteliklere sahip olduğunu, \%22,4'ünün ise cinsiyetçi kalıpyargılardan uzak olduğu sonucuna ulaşmışlardır (Alabay ve Güder, 2014, s.5-6).

Sapsağlam (2018) okul öncesi çocuklarının oyun tercihleri üzerine yaptığı çalışmada 3 yaş çocuklarının evcilik, araba oyunlarını diğer yaş gruplarına göre daha fazla seçtikleri görülmektedir. Bu oyunların tercih edilmesinin nedeninin bu yaş grubunun dijital oyunlar ile alakalı yeterli tecrübeye sahip olmama durumu ile ilgili olduğu ileri sürülmüştür. Aynı araştırmada ilk çocukluk dönemlerinden başlayarak dijital aygitlarla tanışan çocukların, oyun oynama ve eğlenme biçimlerinin de farklılaştığı ve yaşları büyüdükçe elektronik aygıtlarla oynanan oyunlara yöneldikleri 
belirtilmektedir (Sapsağlam, 2018, s.1129-1130). Erboy ve Vural (2010)'in 4. ve 5. sınıf öğrencileri ile yaptıkları araştırmada ise, 5 . sınıf öğrencilerinin 4. sınıf öğrencilerine göre bilgisayar üzerinden oyun oynamayı bırakmakta daha fazla zorluk çektiklerini ortaya koymaktadır (Erboy ve Vural, 2010, s.52). Teknolojide yaşanan baş döndürücü gelişmeler neticesinde geleneksel bilgisayar uygulamalarının yerini mobil cihaz uygulamaları almaya başlamıştır. Mobil cihazlar sayesinde bu uygulamalara zaman mekan sınırlaması olmaksızın erişilebilme imkanının yanında kullanıcıların ilgilerine özel birçok uygulama sunulabilmektedir (Özkoçak, 2016, s.108). Mobil uygulamalarla sosyal paylaşım sitelerinde paylaşım yapılabilmekte, çevrimiçi oyunlar oynanabilmekte, bankaya gitmeden bankacılık işlemleri vb. gerçekleştirilebilmektedir (Bilgili, 2014, s.10). Tercih edilen uygulamaların başında oyun uygulamaları gelmektedir. 2014 yılında telefonlarda en fazla zaman harcanan uygulamaların oyunlar olduğu belirtilmektedir (Mobilike, 2014, s.16).

Günümüzde artık her yaş grubundan bireye hitap eden elektronik oyunlar, gündelik yaşamın bir parçası haline gelmiş durumdadır (Keskin, Şahin ve Yurdugül, 2017). Eğitim, Kültür ve Araştırma Müdürlügü̈'nün 2018 yılı eSpor Raporuna göre, Türkiye'de dijital oyunlardan elde edilen toplam gelir 878,8 milyon dolardır. Rapora göre Türkiye, dünyada dijital oyunlar piyasasında 18. Sirada yer almaktadır (ESpor Raporu, 2018: 49). 2019 Dijital Oyunlar Raporu'na göre Türkiye'de 30 milyona yakın insan bilgisayar, telefon ve konsollardan oyun oynamaktadır (Dijital Oyunlar Raporu, 2019, s.10).

\section{Dijital Oyunlar ve Cinsiyet}

Cinsiyet ve dijital oyunlar ile alakalı araştırmalar incelendiğinde cinsiyetin, oyun oynama süresinin, oyun türü tercihlerinin belirleyicisi olarak ele alındığı görülmektedir (Gökkaya ve Deniz, 2014; Pala ve Erdem, 2011; Irmak ve Erdoğan, 2016; Crawford, 2005; Bryce and Rutter, 2003). Fromme (2003) 1000 'den fazla okul çocuğu ile ilgili yaptığı araştırmasında bu çocuklardan yalnızca \%2.2'sinin hiç bir şekilde dijital oyun oynamamış olduğunu, erkek çocuklarının \%56'sının, kız çocuklarının ise \%29'unun düzenli olarak dijital oyunlara katıldığını ortaya koymuştur (Fromme, 2003, s.8). Bununla birlikte dijital oyunlara katılım yalnızca gençlerle sınırlı 
değildir. ESA (2019) verilerine göre $\mathrm{ABD}^{\prime}$ de dijital oyun oynayan kadınların yaş ortalaması 34 iken, erkeklerin yaş ortalaması 32' dir. Dijital oyunlara katılan yetişkinlerin oyun oynarken $\% 60$ ' 1 nın ak1llı telefonları $\% 52$ 'sinin kişisel bilgisayarları kullandığı ileri sürülmektedir. Dijital oyunlara katılanların \%46'sını kadınlar, \%54'ünü ise erkek katılımcılar oluşturmaktadır (Entertaintment Software Association, 2019).

Crawford (2006), üniversite öğrencileri üzerinde yaptığı araştırmada kadınların erkek yaşıtlarına oranla dijital oyun oynama olasılıklarının daha az olduğunu saptamıştır. Araştırma sonuçlarına göre, kadınlar erkeklere kıyasla dijital oyunlara daha az katılmaktadır (Crawford, 2005, s.266-268). Özellikle 80'lerde video oyunlarının büyük bir çoğunluğunun erkeklere yönelik olduğu belirtilmektedir (Colwell, Grady and Rhaiti, 1995, s.195; National Geographic Belgesel). Bu durum, piyasaya sürülen oyun türlerinin erkeklere yönelik olması şeklinde yorumlanmıştır. National Geographic'in 1980'lerin döneme damgasını vurmuş aygıtlarının ele alındığı belgeselinde kadın bir görüşmeci, Pacman'dan önce video oyunu diye bir şey olduğunu bilmediğini, video oyunlarının tam anlamı ile bir erkek dünyası olduğunu ifade etmektedir. Pacman ile birlikte video oyunlarında kadınların daha görünür olmaya başladığı ve talep doğrultusunda cinsiyeti kadın olan Ms. Pacman'in piyasaya sürüldüğü belirtilmektedir. Kadınlar, Ms. Pacman oyunu ile dijital oyun dünyası içinde yer edinmeye başlamış olsalar da (NatGeo Belgesel) dijital oyunlar çoğunlukla erkeklerin egemenliğinde olan bir alan olarak görülmeye devam etmektedir (Cassell and Jenkins, 1998, s.35).

Oyunlar genellikle erkek karakterler üzerinden erkek temaları ile ilerlemekte ve kadın karakterlerden çoğunlukla yoksundur. Oyunlardaki kadın karakterlerin mevcudiyeti durumunda ise bu kadın karakterlerin oyunlarda çoğunlukla cinselleştirildiği ya da görece pasif olduğu biçiminde tasvir edilmektedir (Bryce and Rutter, 2003, s.6; Kafai, 1996, s.14). Toplumsal cinsiyetin inşasına yönelik temel bir örnek sunan dijital oyunlarda kadınlar, kurtarılması gerektiği zamanlar dışında, oyunlarda nadiren görülmektedir (Cassell and Jenkins, 1998, s.7). Provenzo (1991) yüzlerce arcade oyunu incelediği çalışmasında bu oyunların \%92'sinin hiçbir şekilde kadın rolü içermediğini, kalan \%8'lik oranın \%6'sının tehlike altında olan kadınlardan oluştuğunu, geriye kalan \%2'lik kısımda ise oyun içinde aktif rol oynayan kadınlar olduğunu ortaya koymaktadır. Ancak 
bu aktif rolleri oynayan kadın temsilleri Ms. Pacman ve Mama Kangaroo gibi insan olmayan figürlerdir (Provenzo, 1991 akt. Cassell and Jenkins, 1998, s.7).

Günümüze yaklaştıkça dijital oyunların doğasında meydana gelen teknolojik ve kültürel değişiklikler ile birlikte birçok dijital oyunun tema ve içerikleri daha az cinsiyetli hale gelmiş ve oyun içi kadın karakterlerde artış, erkek egemen temalarda azalma olmuştur (Bryce and Rutter, 2003, s.9). Bu değişimlere paralel olarak dijital oyunlara katılan kadın sayısında da artış olduğu görülebilmektedir. ESA'nın 2006 ve 2019 yılı verileri karşılaştırıldığında 2006 yılında ABD'de dijital oyunlara katılanların \%38'lik kısmını oluşturan kadınların oranı (ESA, 2006, s.3) 2019 yılında \%46'ya yükselmiştir (ESA, 2019, s.7). Türkiye Oyun Sektörü Raporu (2019)'na göre ise dijital oyun oynayanların $\% 42,8$ ' ini kadınlar $\% 57,2$ 'sini ise erkekler oluşturmaktadır (Gaming In Turkey, 2019, s.43).

Dijital oyun tercihlerini ve sürelerini etkileyen değişkenlerden biri olarak ele alınan cinsiyet (Prensky, 2001 akt. Pala ve Erdem, 2011: 55) literatürümüzde kişilerin oyunları tercih etme sebepleri ve oyun türlerinin belirleyici değişkeni olarak ele alınmıştır (Duman ve Temel, 2011, s. 279; Durdu, Hotomaroğlu ve Çağıltay, 2005; İnal ve Çağıltay, 2005, s.7-8).

Erkek çocuklarının dijital oyunlara kız çocuklarından daha fazla zaman harcadığ ileri sürülmektedir (Funk, 1993, s.89; Roberts, Foehr, Rideout and Brodie, 1999, s.48; Subrahmanyam, Greenfield, Kraut, Gross, 2001, s.10). Bilgisayar oyunları erkekler arasında popüler olma özelliğini göstermeye devam etmektedir (Crawford, 2005, s.267; Subrahmanyam et al., 2001, s.12). Ankara Kalkınma Ajansı'nın Dijital Oyun Sektörü Raporu (2016) 'na göre de dijital oyunlara dahil olan toplan kitlenin çoğunluğunu erkekler oluşturmaktadır.

Cassell ve Jenkins (1998) ve Bryce ve Rutter (2003), kadınların dijital oyunlardaki azlığına ilişkin çeşitli açıklamalar sunmaktadır. İlk olarak kadınların serbest zaman aktivite seçimlerinin erkeklere oranla nispeten daha kısıtlı olduğunu ve olmaya devam ettiği görülmektedir (Deem, 1982, s.44-45; Shaw, 1994, s.18; Wearing, 1998, s.177-178). Ekonomik kısıtlanmışlıklar, ev ve çocuk bakımı gibi işlerin kadınlara yüklenişi, sınırlı serbest zaman süreleri vb. gibi birçok faktör bu durumun başlıca nedenlerini oluşturmaktadır (Crawford, 2005, s. 260). Ayrıca teknolojiye erişim olanağının da kız çocuklarının aleyhine eşitsiz olduğu ileri sürülmektedir. Birçok 
çalışma, okullarda bilgisayar teknolojilerinde erkeklerin egemenliği olduğunu ve ilerleyen yıllarda bilgisayarların çoğunlukla erkeklerin iş veya eğlence araçları olarak görüldüğünü ve bu nedenle de kadınlar arasında popülerlik kazanmadığını göstermektedir (Greenfield, 1996, s. 7; Kiesler, Sproull and Eccles, 1985, s.452). Armstrong (2016) ‘un belirttiğine göre kadınlar $\mathrm{ABD}^{\prime}$ deki işgücünün \%45'ini oluşturmalarına rağmen ileri teknoloji ve bilgi işlem endüstrisinde çalışan kadınların oranı \%26'dır (Armstrong, 2016, s.106). Kinder (1991), dijital oyunların erkek ilgi alanları etrafında oluşturulduğunu ve öncelikle erkek izleyicilerin ilgisini kazanmak için tasarlandığını ileri sürmektedir (Kinder, 1991, s.209-210).

Öte yandan alanyazında cinsiyete göre dijital oyun türü tercihlerinin de farklılaştığını gösteren çalışmalar da bulunmaktadır. Can (2003) çalışmasında kız ve erkek çocuklarının dijital oyun türü tercihlerine yönelik yapılan araştırmaları tablolaştırarak özetlemiş, cinsiyetin dijital oyun türü tercihlerinin önemli bir belirleyicisi olduğuna işaret etmektedir (Can, 2003, s.35).

Tablo 2. Kız ve Erkeklerin Dijital Oyun Tercihleri ile Alakalı Yapılan Çalışmalar (Can, 2003, s.35).

\begin{tabular}{|c|c|c|}
\hline Kizlar & Erkekler & Kaynaklar \\
\hline Gerçekçi tema ve roller & Fantastik tema ve roller & $\begin{array}{l}\text { (Subrahmanyam vd., 2001; Subrah- } \\
\text { manyam ve Greenfield, 1999) }\end{array}$ \\
\hline Gerçekliği az olan fanteziler & Gerçekçi insan vahşeti & $\begin{array}{l}\text { (Buchman ve Funk, 1996; Funk, } \\
\text { 2001) }\end{array}$ \\
\hline Vahşi olmayan oyunlar & Vahşi oyunlar & $\begin{array}{l}\text { (Subrahmanyam ve Greenfield, } \\
\text { 1999) }\end{array}$ \\
\hline İlişki & Rekabet & $\begin{array}{l}\text { (Prensky, 2001: 140; Subrahman- } \\
\text { yam ve Greenfield, 1999) }\end{array}$ \\
\hline Beraberlik & Rekabet & $\begin{array}{l}\text { (Prensky, 2001: 140; Subrahman- } \\
\text { yam ve Greenfield, 1999) }\end{array}$ \\
\hline Yapıci oyunlar & Y1kici oyunlar & (Gorriz ve Medina, 2000) \\
\hline Düşündüren oyunlar & $\begin{array}{l}\text { Eğlendiren, heyecan- } \\
\text { landıran ve iyi grafikleri } \\
\text { olan oyunlar }\end{array}$ & (Yelland ve Lloyd, 2001) \\
\hline Eğlenceli oyunlar & Spor oyunları & $\begin{array}{l}\text { (Buchman ve Funk, 1996; Funk, } \\
\text { 2001) }\end{array}$ \\
\hline Az sayıda oyunculu oyunlar & Çok oyunculu oyunlar & $\begin{array}{l}\text { (Subrahmanyam ve Greenfield, } \\
\text { 1999) }\end{array}$ \\
\hline
\end{tabular}

Can (2003)'ın oluşturduğu tablo incelendiğinde erkeklerin vahşi, rekabet ve şiddet içeren oyun türlerini tercih ettiği, kızların ise şiddet 
içermeyen ve vahşet içermeyen oyunları tercih ettiği görülmektedir. Pala ve Erdem (2011) dijital oyun tercihi ve oyun tercih nedenlerini demografik bilgiler ile inceledikleri çalışmalarında cinsiyet ile dijital oyun tercihleri ve oyun tercih nedenleri arasında anlamlı bir ilişki olduğu sonucuna ulaşmışlardır. Erkekler gerçek ve tüm zamanları kapsayan oyunları oynama konusunda ayrım yapmazken heyecanlı, görsel kalitesi yüksek, gerçek yaşama yakın, stratejik planlama yapabilecekleri oyun tercih ederken; kızlar daha çok gerçek zamanlı ve heyecan veren oyunları tercih etmektedir. Ayrıca erkelerden farklı olarak zihinsel beceri gerektiren, tek kişilik ve kişiselleştirebildikleri tercih etmişlerdir ve strateji oyunlarını hiç tercih etmemişlerdir (Pala ve Erdem, 2011, s.66).

Tablo 3. Kiz ve erkeklerin oyun tercihleri (Pala ve Erdem, 2011: 66).

\begin{tabular}{ll}
\hline Kızlar & Erkekler \\
\hline Gerçek zamanlı oyunlar & Gerçek ve tüm zamanlı oyunlar \\
Heyecanlı & Heyecanlı \\
$\begin{array}{l}\text { Zihinsel beceri gerektiren oyunlar } \\
\text { Tek kişilik ve kişiselleştirebilecekleri } \\
\text { oyunlar }\end{array}$ & Stratejik planlama yapabilecekleri oyunlar \\
\hline
\end{tabular}

Taylan, Topal ve Ayas (2018)'ın lise öğrencileri üzerinde yaptıkları araştırma, erkek öğrencilerin \%90'ının kız öğrencilerin ise \%52'sinin dijital oyun oynadığını ve erkek öğrencilerin kız öğrencilerden daha fazla şiddet içeren türde oyunlara katıldıklarını göstermektedir (Taylan, Topal ve Ayas, 2018, s, 66). Benzer biçimde Karahisar (2014)'ın yaptığı araştırmaya göre erkek çocukları savaş, macera, saldırganlık ve kavga içeren oyunları tercih ederlerken, kız çocukları daha çok eğitsel oyunları tercih etmektedir. Ayrıca erkekler kızlara oranla internette daha fazla oyun oynamaktadırlar (Karahisar, 2014, s.92).

\section{Sonuç}

Bu çalışmada görülmektedir ki farklı amaçlar doğrultusunda oynanan oyunlar her geçen gün yeni bir nitelik kazanmaktadır. Örneğin oyunlar, 1990 ve 2000'lerin başında cep telefonlarında sadece skor ve seviye geçme amaçlı tek formatta bir yılan ile oynanılan "Snake" gibi oyunlardan karakter seçilebilen gerçek kişilerin dijital ortamda birbirleri ile rekabet halinde 
olduğu ve büyük turnuvalar düzenlenen PUBG gibi oyunlara dönüşmüştür.

Teknolojik gelişmelerin dijital oyunlar üzerindeki etkisi 21.yüzyılın başından itibaren artmakta ve son yıllarda da bu etki doğrultusunda dünya genelindeki birçok spor kulübü elektronik spor ile ilgili çeşitli yatırımlar gerçekleştirmektedir (Üçüncüoğlu ve Çakır, 2017 s.43). Toplumun birçok kesiminin ilgisini çekmeyi başarmış dijital oyunlar birçok yaş grubundan ve cinsiyetten kişiler tarafından da deneyimlenmeye devam etmektedir.

Cinsiyet ve dijital oyunlar üzerine yapılan araştırmalar incelendiğinde ise bu iki kavram arasında anlamlı bir ilişki olduğu açıktır. Günümüzden kırk beş yıl önce Rheingold ve Cook (1975)'un erkek ve kız çocuklarının oyuncak tercihi ve ailelerin çocuk odalarındaki dekorasyonları üzerine yaptığ1 araştırmada oyuncak tercihlerinin ve çocuk odası dekorasyonlarının cinsiyet kapsamında farklılık gösterdiğini aynı şekilde günümüzden yirmi dokuz yıl önce de, Cassell ve Jenkins (1998)'in aktardığına göre Provenzo (1991) yüzlerce arcade oyununu araştırdığ1 çalışmasında oyunların \%92'sinin erkek karakterler barındırdığı sonucuna ulaşmıştır. Günümüze yaklaşıldığında ise Ankara Kalkınma Ajansı'nın Dijital Oyun Sektörü Raporu (2016)'na göre dijital oyunlardaki kitlenin çoğunluğunu erkekler oluşturmaktadır. Farklı zamanlarda yapılan bu araştırmaların sonuçlarına göre gerek geleneksel oyuncakların gerekse de dijital oyunların cinsiyet kapsamında benzer tarafın lehine işlemesi toplumsal cinsiyet rollerinin her defasında yeniden üretildiğini göstermektedir.

Kadınların serbest zaman aktivitelerinde bulunma girişiminde ya da esnasında birçok sınırlandırma ile karşı karşıya olması toplumdaki sosyal statü eşitsizliğinin yanında kadın ve erkeklerin serbest zaman etkiliklerinin sayısı ve içeriğine de yansımaktadır. Bu sınırlandırmanın ise daha çok gelişmemiş ülkelerde belirgin bir şekilde görüldüğü bilinmektedir. Konu ile ilgili birçok çalışma da kadının, toplumsal yapının kadınlara atfettiği sorumluluklar sebebiyle kadınların serbest zaman aktivitelerine erkeklere oranla daha az katılma olanağına sahip olduğunu göstermekte (Russell, 2009, akt., Görgülü, 2019 s.13) ve çok küçük yaşlardan itibaren kullanılan oyuncaklarda bile cinsiyetin oyun ve oyuncak türlerinin seçiminde belirleyici bir etkisi olduğunu, konu ile ilgili yapılan 
araştırmaların sonuçları gözler önüne sermektedir. Çok küçük yaşlardan itibaren aile aracılığ ile çocuklara kazandırılan toplumsal cinsiyet rolleri, çizgi filmler, reklamlar, oyun ve oyuncaklarla pekiştirilmektedir.Nitekim oyuncak ve dijital oyun üreticilerinin de bu doğrultuda hareket ettiği görülmekte ayrıca çalışmamızda verilen örneklerden yola çıkıldığında reklamlarda da benzer şekilde kız ve erkek çocukların ileride nasıl bir birey olacaklarına dair mesajlar da oyun-oyuncak tanıtımında renklerin kullanımı gibi birçok gösterge ile ebeveyn ve çocuklara aşılanmaktadır.

Öte yandan bilgisayar çağında teknolojik ilerlemenin gerisinde kalmak istemeyen değişim ve gelişime adapte olan birçok ülke dijital oyunların mega bir sektör haline geldiğinin bilincedir. Bu sektörün tüm dünyada ve ülkemizde büyüyerek etkisini daha çok artıracak bir duruma gelmesi ise kaçınılmazdır. Alanın gerisinde kalmamak ve değişen dünyaya ayak uydurabilmek adına alan ile ilgili daha fazla bilgilendirici ve yararlı çalışma yapmanın da fayda sağlayacağı görüşündeyiz. 


\section{EXTENDED ABSTRACT}

\section{Digital Games as a Leisure Time Activity and Gender \\ * \\ Ümmü Arda- Rabia Kaya- Veli Ozan Çakır \\ İstanbul University-Cerrahpaşa - Nişantaşı University - Alanya Alaaddin Keykubat University}

The game, which contributes positively to the skills and intelligence development of individuals from early ages to the later stages of life, not only helps people have a good time, but also allows them to have fun. The play has existed with its own meanings from the past to the present, and has also assumed the role of transferring culture to the next periods. On the other hand, the relationship of the game with gender has often differed in terms of the form or purpose of the games since ancient times. With the modernization, the game became widespread and entered into a transformation. Both the shortening of working hours and the irreversible inclusion of technological devices in daily life have caused great changes in the gaming habits of individuals. Today, the game is both an enjoyable and entertaining tool within the scope of recreational sports and a business that has the potential to generate economic income within the scope of elite sports.

Increasing demands for games that allow individuals to spend their leisure times in entertainment encourage large-scale investments in this field. The PacMan, which took the whole world by storm in the 1980s, has increased its influence day by day by adding the concept of digital game to its structure after dragging the masses after it. Digital games continue to exist in the form of mega organizations within the scope of esports today. Today, most countries have an esports federation. However, it seems that besides all these developments as in classical games and toys, the games preferred by the genders differ in the digital games.

Sex refers to the biological difference between men and women. Biological differences are culturally interpreted and evaluated in every society. Thus, social expectations are developed regarding which gender will behave how, and what the behavior pattern will be from childhood to adulthood. In this way, gender-based differences and inequalities emerge in society. 
Gender is the meaning and values attributed to the biological differentiation of men and women by ideology. Gender is also a cultural phenomenon, which is the product of the mutual, intertwined and mixed relations of institutions with the social environment. The concept of gender also manifests itself in the selection of games and toys preferred by individuals. There is a strong link between the game, playmate and toy preferences of individuals and their gender role development. When the researches in the literature are examined, it is seen that gender, playing time and game type are considered as the determinant of preferences.

Digital games, which were previously considered a male-dominated field, are among the activities that many women are involved in today. Digital games, which have managed to attract the attention of many segments of society, continue to be experienced by people of many age groups and genders. However, it is still possible to clearly see the traces of gender in the digital game environment. The majority of the audience in digital games is men. It is claimed that the majority of video games in the 1980s were for men and the effect of this point of view still continues. It is also claimed that women are less likely to play digital games than their male peers.

The games generally proceed with male themes through male characters. The results of the studies carried out also support this observation. It is further argued that digital games are created around male interests and are primarily designed to gain the attention of male audiences.

Gender is also an important determinant of digital game genre preferences. While girls prefer games with more realistic themes and roles, boys prefer games with more fantastic themes. Compared to girls, it is argued that boys tend to engage in more violent and competitive destructive games. On the other hand, girls prefer non-competitive, entertaining and non-violent games.

In this study, it is seen that the games played for different purposes gain a new quality day by day. For example, in the 1990s and early 2000s, games such as "Snake", which is played with a snake in a single format for the purpose of scoring and leveling on mobile phones, turned into games such as PUBG, where real people who can choose characters from each other in competition with each other in the digital environment and big tournaments are held. 
Gender roles, which are brought to children through the family from a very young age, are reinforced with cartoons, advertisements, games and toys. In addition, toy and digital game manufacturers act in this direction. Similarly, in advertisements, messages about how girls and boys will become individuals in the future are instilled in parents and children with many indicators such as the use of colors in the promotion of games and toys.

\section{Kaynakça/References}

Abt, C. C. (1987). Serious games. New York: University Press of America.

Akgöl, O. (2019). Spor endüstrisi ve dijitalleşme: Türkiye'de espor yapılanması üzerine bir inceleme. TRT Akademi. 4(8) 206-225.

Akgül, H. ve Öztürk, C. (2004). Oyun ve oyuncağın tarihsel gelişimi. Çocuk Forumu. 7(1), 53-58.

Akın, E. (2008). Elektronik spor: Türkiye'deki elektronik sporcular üzerine bir araştırma. (Yayımlanmamış Yüksek Lisans Tezi). Anadolu Üniversitesi, Sağlık Bilimleri Enstitüsü, Eskişehir.

Alabay, E. ve Güder, S. Y. (2014). Oyuncak reklamlarının mesaji: "Bana cinsiyetini söyle, sana oyuncağını söyleyeyim..." Akdeniz Üniversitesi I. Dil, Kültür ve Edebiyat Çalıştayı, Antalya, 1-16.

Altuntaş, B. ve Karaarslan, M. (2017). Kullanıcllarm mobil oyun tercihinde etkili olan faktör düzeylerinin öneminin belirlenmesi. Uluslararası İktisadi ve İdari İncelemeler Dergisi, 19, 277-298. Doi: https://doi.org/10.18092Lulikidince. 321570

And, M. (2012). Oyun ve bügü: Türk kültüründe oyun kavramı (3. Baskı). İstanbul: Yapı Kredi Kültür Yayınları.

Ankara Kalkınma Ajansı (2016). Dijital oyun sektörü raporu. http://www.ankaraka.org.tr/archive/files/yayinlar/ankaraka-dijital-oyun-sektoru.pdf (Erişim Tarihi: 24.04.2020).

Armstrong, N.S. (2016). Leveling the playing field: gender inclusive design for single and multiplayer computer role-playing games. (Yayınlanmamış Doktora Tezi). Nova Southeastern University, College of Engineering and Computing, Florida.

Baloğlu, B. ve Davutoğlu, A. (2009). Sporun değişen yüzü. (2. Baskı) İstanbul: Derin Yayınları. 
Bilgili, M. İ. (2014). Adaptif bağlam bilinçli mobil uygulama geliştirme. (Yayımlanmamış Yüksek Lisans Tezi). Gazi Üniversitesi, Bilişim Enstitüsü, Ankara.

Blakemore, J. E. O. and Centers, R. E. (2005). Characteristics of boys' and girls' toys. Sex Roles, 53(9-10), 619-633. Doi: https://doi.org/10.1007/-s11199005-7729-0

Bryce, J. and Rutter, J. (2003). The gendering of computer gaming: experience and space. Lsa Publication, 79, 3-22.

Caillois, R. (1961). Man, play, and games. (M. Barash, Çev.) Chicago: University of Illinois Press. (Orijinal Eserin Yayın Tarihi 1958).

Can, G. (2003). Perceptions of prospective computer teachers toward the use of computer games with educational features in education. (Yayımlanmamıs Yüksek Lisans Tezi). Middle East Technical University, Ankara.

Cassell, J. and Jenkins, H. (1998). Chess for girls: Feminisms and computer games. J. Cassell and H. Jenkins (Der.), From Barbie to Mortal Kombat: Gender and Computer Games, içinde (s. 2-45). London: MIT Press 2-45.

Colwell, J., Grady, C. and Rhaiti, S. (1995). Computer games, self-esteem and gratification of needs in adolescents. Journel of Communication and Applied Social Psychology ,5(3),195-206.Doi: https://doi.org/10.1002/casp. 2450050308

Crawford, G. (2005). Digital gaming, sport and gender. Leisure Studies, 24(3),259-270. Doi: http://dx.doi.org/10.1080/0261436042000290317

Çiftçi, A. M. and Özgün, Ö. (2011). Okul öncesi dönemdeki çocukların oyuncak tercihlerinin ve akran etkileşimlerinin ebeveyn cinsiyet rolleri algisı bağlamında incelenmesi. e-Journal of New World Sciences Academy, 6(3), 2246-2261.

Deem, R. (1982). Women, leisure and in equality. Leisure Studies, 1, 29-46. Doi: https://doi.org/10.1080/02614368200390031

Demirci, A. (2014). Literatür taraması. Y. Arı ve İ. Kaya (Der.), Coğrafya Araştırma Yöntemleri, içinde (s.73-107). Balıkesir: Coğrafyacılar Derneği.

Dijital Dünyada Rekabet, eSpor ve Topluluk Yönetimi Çalıştayı (2017). Sonuç Raporu 7 Mayıs 2020 tarihinde https://www.guvenliweb.org.tr/dosya/GCSvB.pdf adresinden erişildi.

Duman, G. ve Temel, F. (2011). Türkiye ve Amerika Birleşik Devletleri'nde anasınıfına devam eden çocukların oyun davranışlarının incelenmesi. Kırıkkale Üniversitesi Sosyal Bilimler Dergisi, 1(1) , 279-298. 
Durdu, P. Hotomaroğlu, A. ve Çağılttay, K. (2005). Üniversite öğrencilerinin bilgisayar oyunu oynama alışkanlıkları ve oyun tercihleri: ODTÜ ve Gazi Üniversitesi öğrencileri arasında karşılaştırmalı bir çalışma. Eurasion Journal of Educational Research, 19, 66-76.

Ecevit, Y. (2003). Toplumsal cinsiyet ile yoksulluk ilişkisi nasıl kurulabilir? Bu ilişki nasıl çalışılabilir?.Cumhuriyet Üniversitesi Tıp Fakültesi Dergisi, sayı 24(4), 83-88, Özel Eki.

Eğitim, Kültür ve Araştırma Müdürlüğü (2018). E-Spor Raporu. Gençlik Araştırmaları Haber Bülteni: Yeni Ne Var? Sayı:5

Erboy, E. ve Vural, R. (2010). İlköğretim 4. ve 5. sinıf öğrencilerinin bilgisayar oyun bağımlılığını etkileyen faktörler. Ege Eğitim Dergisi, 11(1), 39-58.

Ercansungur, D.O. ve Canbaz, E. (2019). Roger Caillois ve Agôn: Dijital oyundan e-spor'a, 1. Uluslararası Oyun Kongresi Bildiri Kitabı, 203-212.

ESA (2006). Essential facts about the computerand video game industry. 19 Nisan 2020 tarihinde https://library.princeton.edu/sites/-default/files/2006.pdf adresinden erişildi.

ESA (2019). Essential facts about the computerand video game industry. 17 Nisan 2020 tarihinde https:/www.theesa.com/wp-content/uploads/2019/05/ESA Essential facts 2019 final.pdf adresinden erişildi.

Esentaş, M., Güzel, P. ve Vural, M. (2018). Popüler kültürde rekreatif bir etkinlik olarak dijital sporlar. Ankara Üniversitesi Beden Eğitimi ve Spor Bilimleri Dergisi, 20(1), 71-79.

Fox D. and Verhovsek, R. (2002). Micro java game development. Boston: Addison Wesley.

Fromme, J. (2003) Computer games as a part of children's culture. Game Studies, 3(1), 2-23.

Funk, J. (1993). Reevaluating the impact of video games. Clinical Pediatrics, 2, 86-89. Doi: https://doi.org/10.1177/000992289303200205

Gaming In Turkey (2019). Türkiye oyun sektörü raporu. 19 Nisan 2020 tarihinde https://www.gaminginturkey.com/turkiye-oyun-sektoru-raporu-2019.pdf adresinden erişildi.

Gökkaya, Z. ve Deniz, L. (2014). Üniversite öğrencilerinin bilgisayar oyunu oynama alışkanlıkları ve oyun tercihleri Marmara Üniversitesi örneği. The Journal of Academic Social Sciences, 2(6), 58-73. Doi: https://doi.org/10.16992/asos.332 
Görgülü, T. (2019). Kadınların serbest zaman etkinliklerini değerlendirme biçimleri üzerine nitel bir çalışma. (Yayımlanmamış Yüksek Lisans). Manisa Celal Bayar Üniversitesi Sosyal Bilimler Enstitüsü, Manisa.

Greenfield, P. M. (1996) Video games as cultural artifacts, special 1ssue: effects of interactive environment technologies on development. Journal of Applied Developmental Psychology, 15(1),3-12. Doi: https://doi.org/10.1016/0193-3973(94)90003-5

Güder, Y. S. ve Alabay, E. (2016). 3-6 yaş arasındaki çocukların oyuncak tercihlerinin toplumsal cinsiyet bağlamında incelenmesi. Ahi Evren Üniversitesi Kırşehir Ĕ̆itim Fakültesi Dergisi, 2(17), 91-111.

Güder, Y. S. ve Güler Yıldız, T. (2016). Okul öncesi dönemdeki çocukların toplumsal cinsiyet algılarında ailenin rolü. Hacettepe Üniversitesi Eğitim Fakültesi Dergisi, 31(2), 424-466. Doi: 10.16986/HUJE.2016016429

Güneş, G., Tuğrul, B., Ertürk, G. ve Altınkaynak, Ö. Ş. (2014). Oyunun üç kuşaktaki değişimi. The Journal of Academic Social Science Studies, 27, 116.Doi: https://doi.org/10.9761/JASSS2388

Güven, S. (2018). Çocukların oyun tercihleri üzerine bir çalışma. Turkish Studies, 13(27), 795-813. Doi: https://doi.org/10.7827/TurkishStudies. 14335

Güvenli İnternet Merkezi Dijital Oyunlar Raporu. (2019). 16 Nisan 2020 tarihinde https://www.guvenliweb.org.tr/dosya/RjARy.pdf adresinden erişildi.

Huizinga, J. (2006). Homo ludens: Oyunun toplumsal işlevi üzerine bir deneme. (M. A. Kılıçbay, Çev.). İstanbul: Ayrıntı Yayınları. (Orijinal eserin yayın tarihi 1938).

Irmak, A. Y. ve Erdoğan, S. (2016). Ergen ve genç erişkinlerde dijital oyun bağımlılığı: Güncel bir bakış. Türk Psikiyatri Dergisi, 27(2), 128-137. Doi: 10.5080/u13407

İnal, Y. ve Çağıltay, K. (2005). İlköğretim öğrencilerinin bilgisayar oyunu oynama alışkanlıkları ve oyun tercihlerini etkileyen faktörler. Ankara Özel Tevfik Fikret Okulları, Eğitimde Yeni Yönelimler II. Eğitimde Oyun Sempozyumu, 14 Mayıs 2005.

Kafai, Y.B. (1996) Electronic play worlds: gender differences in children's construction of video games. Y.B. Kafaiand and M. Resnick (Der.). Constructionism in Practice: Designing, Thinking, and Learning in a Digital World içinde 25-38. NJ: Ablex, Mahwah. 
Karahisar, T. (2014). İnternette çocukları bekleyen riskler ve medya okuryazarlığ1. The Turkish Online Journal of Design, Art and Communication, $4(4), 82-95$.

Kemiksiz, R. C. (2019). Çeorimiçi bağımlılı̆̆ın habitatı: Çeorimiçi oyuncuların espor faaliyetleri ve oyun bă̆ımlılığı ilişkisi. (Yayımlanmamış Yüksek Lisans). İstanbul Üniversitesi Sosyal Bilimler Enstitüsü, İstanbul.

Keskin, S., Şahin, M. ve Yurdugül, H. (2017). Ortaokul öğrencilerinin oyun ve oyuncu etkileşiminin cinsiyete dayalı olarak incelenmesi. 11. Uluslararası Bilgisayar ve Öğretim Teknolojileri Sempozyumu (ICITS 2017), Malatya, Türkiye.

Kiesler, S., Sproull, L. and Eccles, J. (1985) Pool halls, chips and war games: women in the culture of computing. Psychology of Women Quarterly, 4, 451-462. Doi: https://doi.org/10.1111/j.1471-6402.1985.tb00895.x

Kinder, M. (1991) Playing with power in movies, television and video games: from muppet babies to teenage mutant ninja turtles. Berkeley: University of California Press.

Kirriemuir, J. (2002). Video gaming, education and digital learning technologies. D-Lib Magazine, 8(2), 1-12.. http://www.dlib.org/dlib/february02/kirriemuir/02kirriemuir.html

Letranchant, C., Laure, J., Maureau, G., Trioux, L. and Hota, M. (2016). The societal impact of children genderization in advertisement. IESEG Working Paper Series 2016-MKT-08. https://www.ieseg.fr/wp-content/uploads/2012/03/2016-MKT-08 Hota.pdf

Mobilike. (2014).17 Nisan 2020 tarihinde https://www.slideshare.net/webrazzi/mobilike-madreport-2014-2-ceyrek adresinden erişildi.

National Geographic 80'ler Müthiş Aygitlar Belgeseli, 18 Nisan 2020 tarihinde https://www.youtube.com/watch?v=i33uu3 1Ipo adresinden erişildi.

Nick, T. (2014, Kasım 16 ). This was the World's first cellphone with a game loadedon it. 8 Mayıs 2020 tarihinde https://www.phonearena.com/news/This-was-the-worlds-first-cell-phone-with-a-game-loaded-onit id62920 adresinden erişildi.

Onur, B. (1992). Oyuncaklı dünya. Ankara: V Yayınları.

Özkoçak, Y. (2016). Türkiye' de akıllı telefon kullanıcılarının oyalanma amaçlı tercih ettikleri mobil uygulamalar. Global Media Journal TR Edition, 6 (12), 106-130. 
Pala, F. K. ve Erdem, M. (2011). Dijital oyun tercihi ve oyun tercih nedeni ile cinsiyet, sınıf düzeyi ve öğrenme stili arasındaki ilişkiler üzerine bir çalışma. Journal of Kirsehir Education Faculty, 12(2), 53-71.

Pilten, P. ve Pilten, G. (2013). Okul çağı çocuklarının oyuna ilişkin algılarının değerlendirilmesi. Mersin Üniversitesi Eğitim Fakültesi Dergisi, 9(2), 1531. Doi: https://doi.org/10.17860/efd.99917

Rheingold, H. L. and Cook, K. V. (1975). The contents of boys' and girls' rooms as an index of parents' behavior. Child Development, 46, 459-463. Doi: https://doi.org/10.2307/1128142

Roberts, D. F., Foehr, U. G., Rideout, V. J., and Brodie, M. (1999). Kids and media at the new millennium: A comprehensive national analysis of children's media use. Menlo Park, CA: A Kaiser Family Foundation Report,.

Salen, K. and Zimmerman, E. (2004). Rules of play: Game design fundamentals. Cambridge: MIT Press.

Sapsağlam, Ö. (2018). Okul Öncesi dönem çocuklarının değişen oyun tercihleri. Ahi Evran Üniversitesi Kırşehir Eğitim Fakültesi Dergisi, 19(1), 11221135.

Sezici, E. ve Yiğit, D. (2019). Okul öncesi çocukların oyuncak tercihleri, oyun davranışları ve sosyal duygusal uyumu arasındaki ilişkinin değerlendirilmesi. Hemşirelik Akademik Araştırma Dergisi, 5, 178-187. Doi: 10.5222/jaren.2019.07088

Shaw, S. M. (1994) Gender, leisure and constraint: towards a frame work for analysis of women's leisure. Journal of Leisure Research, 26, 8-22. Doi: https://doi.org/10.1080/00222216.1994.11969941

Subrahmanyam, K., Greenfield, P., Kraut, R. and Gross, B. (2001). The impact of computer use on children's and adolescents' development. Applied Developmental Psychology, 22, 7-30. Doi: https://doi.org/10.1016/S0193$\underline{3973(00) 00063-0}$

Şentuna, B. (2013). Boş zamanlar sosyolojisi. İstanbul: İstanbul Üniversitesi Açık ve Uzaktan Eğitim Fakültesi Yayını.

Taylan, H. H., Topal, M. ve Ayas, T. (2018). Sakarya'daki lise öğrencilerinin dijital oyun oynama eğilimlerinin incelenmesi. Online Journal of Technology Addiction \& Cyber bullying, 5(1), 53-68.

Toker, C. (2015, Nisan 29). Dünyada eSpor. 4 Nisan 2020 tarihinde https://dijitalsporlar.com/makaleler/dunyada-espor adresinden erişildi. 
TÜİK. (2013). 0-6 yaş grubu çocuklarda bilişim teknolojileri kullanımı ve medya. 14 Nisan 2020 tarihinde http://www.tuik.gov.tr/PreHaberBultenleri.do?id=15866 adresinden erişilmiştir.

TÜIK. (2019). Hanehalkı Bilişsim Teknolojileri (BT) Kullanım Araştırması. 14 Nisan 2020 tarihinde http://www.tuik.gov.tr/PreHaber-Bultenleri.do?id=30574 adresinden erişilmiştir.

Üçüncüoğlu, M. ve Çakır, V. O. (2017). Modern spor kulüplerinin espor faaliyetlerine ilgi gösterme nedenleri üzerine bir araştırma. İnönü Üniversitesi Beden Eğitimi ve Spor Bilimleri Dergisi, 4(2), 34-47.

We are Social Digital. (2020). 14 Nisan 2020 tarihinde https://wearesocial.com/digital-2020 adresinden erişilmiştir.

Wearing, B. (1998) Leisure and feminist theory. London: Sage.

Yıldırım, A. ve Şimşek, H. (2016). Sosyal bilimlerde nitel araştırma yöntemleri (10.bs.) Ankara: Seçkin Yayıncılık.

Yılmaz, E. ve Çağıltay K. (2004). "Elektronik oyunlar ve Türkiye." TBD 21. Ulusal Bilişim Kurultayı, Ankara.

\section{Kaynakça Bilgisi / Citation Information}

Arda, Ü., Kaya, R., ve Çakır, V. O. (2021). Serbest zaman etkinliği olarak dijital oyunlar ve toplumsal cinsiyet. OPUS-Uluslararası Toplum Araştırmaları Dergisi, 17(38), 5791-5818. DOI:10.26466//opus.748560 